of your sensory tests. What you seem to have overlooked is that in the acute stage of the high lesion there is the paralytic vasodilation as the vasoconstrictors are paralysed, as you know, and that makes the changes in the tone of the trachea as it does in the urethra in more distal cord lesions. Hence the comparison with the pressure due to indwelling urethral catheter resulting in mucosal damage.

ChaIrman. Before we move on, perhaps I may have the privilege of throwing one last thought at this question. We've talked about the materials of which the tube are constituted, we've talked about the manner in which the balloon blows up, but we have not discussed the possibility of the endotracheal tube being dragged by the weight of the connecting tube, so that we are talking about a pressure sore between the end of the tube and the lumen of the trachea. Now, I think we've all been dissatisfied to see tubes dragging; even with safety pins and pillows and goodness knows what it still happens. I am sure this is familiar to many of you, but I do want to put this in. The Bennett Respiratory Company have recently produced a new model which incorporates an articulated arm between the body of the respirator and the end of the tube. And with this balanced articulated arm one can position and maintain one's tracheostomy tube centrally down the lumen. This could be yet another factor in the genesis of these lesions.

\title{
POSTURAL VARIATIONS OF THE CAPACITY IN TETRAPLEGICS
}

\author{
By J. V. Forner Valero, D.Phys.Med.(London) \\ Centro de Rehabilitacion y Traumatologia, \\ Ciudad Sanitaria 'La Fe', Valencia, Spain
}

\section{ABBREVIATED}

This short paper, 'A Study on Changes of Vital Capacity of the Lung by Changing the Patient's Position', was carried out in five patients with cervical injuries: one complete lesion below $\mathrm{C}_{4}$, one complete below $\mathrm{C}_{5}$, one complete below $\mathrm{C} 6$, one complete below $\mathrm{C}_{7}$ and two incomplete below C6. This is an important problem, as many of these patients have respiratory trouble and yet, on the other hand, have to be turned or put in different positions to avoid pressure sores.

Except in high cervical injuries with partial paralysis of the diaphragm there is no or little dyspnoea, unless respiratory infection is present. A simple bronchitis may kill a cervical patient, due to his inability to cough.

Method. To assess the influence of position on the ventilatory capacity of patients with cervical lesions, spirograms were carried out in various positions: supine, prone, lateral, head down and head up positions (the latter up to $45^{\circ}$ ).

Result. The values were found as low as $22 \cdot 2$ per cent. of normal values in the patient with $\mathrm{C}_{4}$ lesion in sitting position, and as high as 84.9 per cent. in the head-down position in the $\mathrm{C}_{7}$ lesion. The maximum mean value was found in the head-down position $(73.2$ per cent.) and the minimum in sitting position (49 per cent.). In the prone position, the values are much lower than in the supine position and the prone position is not a satisfactory position for tetraplegics with respiratory trouble. In fact, it should be avoided. In both lateral positions, the values found were similar to the value found in the supine position. Finally, the values of E.R.V. (expiratory reserve volume) are low, due to the absence of the expiratory muscles. 